\title{
RETOS Y PERSPECTIVAS DE LA PROTECCIÓN DEL PATRIMONIO CULTURAL EN PERIODO DE CONFLICTO ARMADO ANTE EL 50o. ANIVERSARIO DE LA CONVENCIÓN DE LA HAYA (1954-2004)*
}

\author{
Rosario DOMÍNGUEZ MATÉS**
}

RESUMEN: La eficacia de la Convención relativa a la Protección de Bienes Culturales en Caso de Conflicto Armado de 1954 se convirtió en materia de preocupación internacional en los años noventa del siglo pasado, principalmente durante la guerra Irak-Kuwait y la guerra de la antigua Yugoslavia, de tal manera que en 1999 se aprueba un Segundo Protocolo Adicional a la misma. No obstante los loables elementos de cambio expresados en este Segundo Protocolo, en vigor desde marzo de 2004, los excesos cometidos bajo la rúbrica de 'imperiosas necesidades militares' y la negligencia estatal en la aplicación de los principios y obligaciones asumidos, hacen que este 50o. aniversario de la Convención de 1954 represente un punto de inflexión para valorar desafíos y perspectivas de futuro.

ABSTRACT: The effectiveness of the Convention to the Protection of Cultural Property in the Event of Armed Conflict of 1954 became of international concern in the ninetees of last century, mainly during the Iraq-Kuwait war and the old Yugoslavia war, in such a way that in 1999 a Second Additional Protocol is approved. Despite the praiseworthy expressed elements of change in this Second Protocol in vigor from the recent month of March of 2004, the excesses made under the heading of 'imperious military necessities' and the state negligence in the application of the principles and assumed obligations force to the fact that this 50o. anniversary of the Convention of 1954 performs to an inflection point where to value challenges and future perspectives.

RÉSUMÉ: L'efficacité de la Convention relative à la Protection des Biens Culturelle en Cas de Conflit Armé de 1954 est devenue une matière de préoccupation international dans les années quatre-vingt-dix du dernier siècle, principalement durant la guerre Irak-Kuwait et la guerre de l'ex Yougoslavie, de telle façon qu'on 1999 s'est adopté un Deuxième Protocole Additionnel à ladite Convention. En dépit des louables éléments de changement exprimés dans ce Second Protocole en vigueur depuis le récent mois de mars de 2004, les excès commis sous la rubrique de 'imprésieuse nécessités militaires' et la négligence étatique dans l'application des principes et obligations assumées font que ces 50o. anniversaires de la Convention de 1954 représente un point d'inflexion où évaluer les défis et perspectives de future.

* El presente trabajo tiene su origen en una ponencia que la autora presentó el día 28 de marzo de 2003 en el Ciclo de Conferencias y Mesas Redondas sobre Globalización: ¿Liberal o Social? celebrado en la Facultad de Derecho de la Universidad de Huelva, España.

** Doctora en derecho. Profesora de derecho internacional público y relaciones internacionales de la Universidad de Huelva, España. Ganadora del Premio en Derechos Humanos 2004, en su versión en español, otorgado por la Academy on Human Rights and Humanitarian Law, Washington College of Law, American University (Washington, D. C., USA).

Anuario Mexicano de Derecho Internacional, vol. V, 2005, pp. $123-152$ 
SUMARIO: I. Alcance y condiciones de los logros que para la protección del patrimonio cultural en periodo de conflicto armado representa la Convención de La Haya de 1954. II. Dificultades para una efectiva protección de los bienes culturales frente a los imperativos de la guerra y la desidia estatal. III. A la búsqueda de un blindaje más perfecto. El Segundo Protocolo Adicional de 1999. IV. Conclusión.

\section{ALCANCE Y CONDICIONES DE LOS LOGROS QUE PARA LA PROTECCIÓN DEL PATRIMONIO CULTURAL EN PERIODO DE CONFLICTO ARMADO REPRESENTA LA CONVENCIÓN DE LA HAYA DE 1954}

La guerra es una vieja enemiga del hombre, del arte y de la cultura. Por razones obvias, no es posible incluir aquí una visión histórica - por breve que fuere- sobre los saqueos, las destrucciones y los botines que a lo largo de los siglos han producido pérdidas, desapariciones y traslados forzosos de miles de obras de arte. No obstante, la realidad actual bien nos puede servir de ejemplo.

Ahora, en un país considerado la cuna de la civilización, la guerra en Irak amenaza a su patrimonio con la destrucción, el saqueo y el tráfico ilegal de antigüedades, tal y como sucedió en la "Guerra del Golfo" de 1990-1991. En efecto, el arco de Tesifonte, situado a unos 30 kilómetros de Bagdad y rodeado de una zona militar; la madrasa Munstansiriya de Bagdad, un impresionante edificio del siglo XIII que albergó la primera universidad del mundo árabe-islámico; el zigurat de Ur, primera ciudad del mundo y gran capital sumeria entre los años 4,000 y 3,500 a. C. y en cuyas proximidades se halla la base aérea y el centro de radares de Tallil; los museos de Nasiriya y Mosul; o las excavaciones en la ciudad de Nínive... fueron alcanzados por los bombardeos y fueron objeto de expolios en la mencionada "Guerra del Golfo".

Al convocar la UNESCO la Conferencia que adoptó la Convención relativa a la Protección de Bienes Culturales en caso de Conflicto Armado de 14 de mayo de 1954, ${ }^{1}$ estaba cumpliendo un mandato específico

1 A iniciativa de los Países Bajos, en el marco de la IVa. Conferencia General de la UNESCO (París, 1949), se adoptó la Resolución 6.42 que proclamó la defensa de los bienes de "valor cultural". Posteriormente, durante la Va. Conferencia General de la UNESCO (Florencia, 1950), el gobierno italiano presentó un anteproyecto de convención que, sobre la base de un previo proyecto de la Oficina Internacional de Museos, se acomodaba a los nuevos tiempos y a los nuevos medios y 
que aparecía ya en el Convenio de Londres de 16 de noviembre de 1945 por el que se creó aquella organización internacional. Los fines de ésta se definían en el artículo 1o. cuando se señalaba que: "La organización tiene por objeto mantener la paz y la seguridad asegurando, mediante la educación, la ciencia y la cultura, la colaboración entre las naciones a fin de garantizar el respeto universal de la justicia, de la ley, de los derechos del hombre y de las libertades fundamentales para todos, sin distinción de raza, de sexo, de lengua o de religión, reconocidos por la Carta de las Naciones Unidas a todos los pueblos". Para esto, se encomienda a la UNESCO, entre otras misiones, la de "velar por la conservación y protección del patrimonio universal de libros, de obras de arte y de otros monumentos de interés histórico o científico, y recomendar a los pueblos interesados la conclusión de acuerdos internacionales para tales fines". ${ }^{2}$

El mandato de carácter general que condujo a la Convención de La Haya 1954 junto a un reglamento anexo para la aplicación de la misma y a su Protocolo sobre la Protección de Bienes Culturales en Caso de Conflicto Armado de 15 de mayo de $1954^{3}$ no está exento, sin embargo, de precedentes históricos que ponen de manifiesto la preocupación sentida por los hombres ante los desastres de la devastación bélica, de forma que

métodos de combate. Estos antecedentes culminaron con una Conferencia Diplomática que se celebró en La Haya entre el 21 de abril y el 15 de mayo de 1954. La Convención de La Haya de 14 de mayo de 1954 entró en vigor el 7 de agosto de 1956. Hasta el 24 de mayo de 2004 había un total de 110 Estados que habían ratificado o se habían adherido a la Convención de La Haya de 1954, el último fue Sri Lanka, el 11 de mayo de 2004.

2 El impulso que ha recibido la protección de los bienes culturales bajo el patrocinio de la UNESCO se ha traducido en un conjunto normativo que, comenzando con esta Convención relativa a la Protección de Bienes Culturales en Caso de Conflicto Armado de 1954, continuó con la Convención sobre las Medidas que deben Adoptarse para Prohibir e Impedir la Exportación y la Transferencia de Propiedad ilícitas de Bienes Culturales de 1970, la Convención sobre Patrimonio Mundial Cultural y Natural de 1972, la Convención sobre la Protección del Patrimonio Cultural Subacuático de 2001, y que ha culminado recientemente con la adopción de la Convención para la Salvaguarda del Patrimonio Cultural Intangible de 2003.

3 Las dificultades expresadas por algunos Estados para la adopción de las disposiciones relativas a la restitución de los bienes llevó a los negociadores de la Conferencia de La Haya de 1954 a conducir estas disposiciones a un Protocolo separado, excluyéndolas del texto de la Convención de La Haya de 1954. Así pues, el objetivo de este Protocolo de La Haya de 1954 consiste en impedir la exportación de los bienes culturales en territorio ocupado y adoptar medidas que aseguren la restitución de los bienes exportados ilegalmente. El Protocolo de La Haya de 1954 entró en vigor el 7 de agosto de 1956. Hasta el 24 de mayo de 2004 había un total de 88 Estados que habían ratificado o se habían adherido a este Protocolo, el último fue Latvia, el 19 de diciembre de 2003. 
ya tuvo su regulación jurídica en los albores de la codificación de las leyes y usos de la guerra. ${ }^{4}$

Sin duda, la Convención de 1954 fue la culminación de todo un esfuerzo común de siglos y constituye "el primer conjunto coherente de normas jurídicas de ámbito universal consagrado enteramente a la protección de los bienes culturales", como bien se manifiesta en su texto, ${ }^{5}$ pero no se consideró como el fin ideal. Quizás por esto, los protocolos adicionales de 1977 abordaron también el problema de la protección de los bienes culturales completando, en cierto modo, algunas de las disposiciones de la Convención de La Haya de 1954 y, posteriormente, es retomado el tema en el Protocolo II sobre prohibiciones o restricciones del empleo de minas, armas trampa y otros artefactos, según fue enmendado en 1996 y en el Protocolo III sobre prohibiciones o restricciones del empleo de armas incendiarias de 1980, ambos adicionales a la Convención sobre Prohibiciones o Restricciones del Empleo de ciertas Armas Convencionales que pudieran considerarse excesivamente Nocivas o de Efectos Indiscriminados de $1980 .{ }^{6}$ Y, es más, este iter normativo no ha terminado aquí, puesto que recientemente se le ha añadido un Segundo Protocolo a dicha Convención de La Haya de 1954, cuya relevancia para nuestro objeto de estudio quedará expuesta a continuación.

Una de las virtudes de la Convención de La Haya de 1954 es la de haber introducido el concepto de "bienes culturales", bajo una noción

4 Así, el artículo 27 del Reglamento de La Haya de 1899 dispone que en los sitios y bombardeos se tomen todas las medidas necesarias para librar, en cuanto sea posible, "los edificios consagrados al culto, a las artes, a las ciencias y a la beneficencia". Y el mismo artículo 27, en su revisión de 1907, añade a la enumeración anterior "los monumentos artísticos". Igualmente, análoga fórmula utiliza el artículo 5 del Convenio (IX) de La Haya de 18 de octubre de 1907 sobre el bombardeo por fuerzas navales en época de guerra. Finalmente, hay que citar el importante precedente del Tratado de Washington relativo a la protección de las instituciones artísticas y científicas y de los documentos históricos, de 15 de abril de 1935 (Pacto Roerich), por virtud del cual los Estados Unidos de América y otros nueve Estados americanos (Brasil, Chile, Colombia, Cuba, El Salvador, Guatemala, México, República Dominicana y Venezuela) establecieron un sistema protector de obras de arte.

5 Camps Mirabet, Nuria, La Protección Internacional del Patrimonio Cultural, Universitat de Lleida, Departament de Dret Públic, mayo de 2000, tesis doctoral inédita, pp. 55 y 56.

6 Sobre el desarrollo histórico del esfuerzo internacional destinado a la protección de la propiedad cultural en periodo de conflicto armado, así como una breve exposición del mismo tras la Convención de La Haya de 1954, véase Toman, Jirí, The Protection of Cultural Property in the Event of Armed Conflict. Commentary on the Convention for the Protection of Cultural Property in the Event of Armed Conflict and its Protocol, signed on 14 May 1954 in The Hague, and on other instruments of international law concerning such protection, Dartmouth, UNESCO Publishing, 1996, pp. 3-36. 
unívoca y más completa que los habitualmente utilizados en sus precedentes históricos y referentes posteriores. ${ }^{7}$ En definitiva, ya no se protegen sólo las obras de arte o los lugares de culto, sino todos aquellos bienes que constituyen en esencia la manifestación de la cultura de un determinado pueblo y que, en razón de su importancia, deben ser preservados de los efectos de la guerra.

En este sentido, el artículo 1o. de la Convención de La Haya de 1954 establece un concepto descriptivo de "bienes culturales" que abarca tres grupos:

a) Los bienes, muebles o inmuebles, que tengan una gran importancia para el patrimonio cultural de los pueblos, ${ }^{8}$ entre los que cita: monumentos arquitectónicos, campos arqueológicos, conjuntos monumentales, obras de arte, manuscritos, libros y otros objetos de interés histórico, colecciones científicas, etcétera.

b) Los edificios que, aún no siendo en sí mismos obras artísticas, están destinados a conservar o exponer los bienes a que se refiere el apartado a). Por ejemplo, museos, grandes bibliotecas, archivos históricos, refugios para proteger bienes culturales de carácter mueble, etcétera.

c) Los "centros monumentales" que son aquellos lugares en que hay una gran concentración de bienes de los comprendidos en $a$ ) y b).

Asimismo, cuando este artículo 1 inicia su exposición sobre lo que se consideran como "bienes culturales" especifica que son los que ya hemos enumerado anteriormente "cualesquiera que sea su origen y propietario" con el fin de dejar claramente establecido que la protección es completa y evitar cualquier duda sobre los bienes que, por ser de propiedad particular, no están habitualmente expuestos a la contemplación general. Además, el concepto es suficientemente amplio toda vez que las enumeraciones que se contienen en $\operatorname{los} \operatorname{apartados} a$ ) y b) del artículo 1o. no son exhaustivas, sino simplemente enumerativas, como lo demuestra el hecho de ser introducida por las palabras "tales como..."

Lo importante es que todos estos bienes gozan de una protección general, y algunos de ellos de una protección especial que tiene por objeto

7 Camps Mirabet, Nuria, op. cit., nota 5, pp. 82-86.

8 Sin duda, la inclusión en la definición del calificativo de "importantes" o "de gran importancia" da lugar a interpretaciones varias $\mathrm{y}$, desde luego, permite un cierto margen de discrecionalidad a las autoridades nacionales competentes a la hora de su calificación. No obstante, como bien se ha expuesto, el criterio "importante" fija un límite mínimo que evita eventuales apreciaciones arbitrarias y, en su caso, abusivas. Ibidem, pp. 84 y 85 . 
su conservación en cuanto son constitutivos de un patrimonio cultural que forma parte de la identidad de cada pueblo. En principio, pues, hay un claro enlace entre esta convención y aquellos otros tratados internacionales que tienen por objeto la protección misma de los derechos esenciales del hombre, entre los que no puede olvidarse el derecho a su propia cultura. No obstante, no sería suficiente esta razón para decidir una protección reforzada, como es nuestro caso. Así pues, lo cierto es que el patrimonio cultural de cada pueblo forma parte del patrimonio cultural de toda la humanidad. Y es, precisamente, el reconocimiento de que los bienes culturales pertenezcan a los intereses comunes de toda la especie lo que motiva su protección $-\mathrm{y}$ en algunos casos, su especial protección_- por esta Convención de La Haya de $1954 .{ }^{9}$

Quizás hayamos tomado nota de que en ningún momento la Convención de La Haya de 1954 nombra a los bienes naturales. En la conferencia se discutió la posible introducción de la protección de "lugares naturales de gran belleza" a propuesta de los Estados Unidos de América y de Japón, pero la idea quedó abandonada como resultado de la opinión de la delegación francesa de que su definición sería compleja puesto que siempre tendría un cariz subjetivo y por el hecho de que los lugares naturales generalmente se restablecen muy rápidamente $(i !)$; no obstante — continuaba su exposición Francia- desde luego el artículo 1 abarcaría tales bienes naturales cuando, por ejemplo, el lugar respectivo era un árbol de especial interés. ${ }^{10}$ De esta forma, aunque el apoyo a la inclusión de los bienes naturales fue amplio, no están protegidos por la Convención de La Haya de 1954. Su motivo estaría en el hecho de que entonces (1954) la preocupación por la preservación y la protección del medio ambiente era prácticamente inexistente. ${ }^{11}$ Habría, pues, que esperar a la Guerra de Vietnam para cambiar de mentalidad.

Ya hemos adelantado que la Convención de La Haya de 1954 dispone una protección general y una protección especial para los bienes cul-

9 Así, los párrafos 2o. y 3o. del Preámbulo de la Convención de La Haya de 1954 que proclaman lo siguiente: "Las Altas Partes Contratantes... convencidas de que los daños ocasionados a los bienes culturales pertenecientes a cualquier pueblo constituyen un menoscabo al patrimonio cultural de toda la humanidad, puesto que cada pueblo aporta su contribución a la cultura mundial" y "Considerando que la conservación del patrimonio cultural presenta una gran importancia para todos los pueblos del mundo y que conviene que este patrimonio tenga una protección internacional". Toman Jirí, op. cit., nota 6, pp. 40-42.

10 Ibidem, p. 53.

11 Ibidem, p. 53. 
turales o, lo que es lo mismo, distingue entre dos tipos de bienes culturales: aquellos que gozan de una protección general y aquellos otros que, por su excepcional importancia, disfrutan, además, de una protección especial. Tal distinción tuvo su origen en las deliberaciones que se produjeron durante la elaboración de la convención en el seno de la conferencia diplomática. Dos tendencias aparecieron claramente definidas: mientras un grupo estimó que la protección debía extenderse a la mayor cantidad posible de objetos, otro grupo mantuvo la tesis de restringir la protección hasta concederla sólo a muy pocos objetos de especial importancia no ya para el país poseedor, sino para toda la humanidad en su conjunto. ${ }^{12}$

La solución adoptada fue fruto, pues, de un compromiso: se protege de forma general a muchos objetos y, de una manera especialmente intensa, a muy pocos objetos de excepcional importancia. De esta suerte, la determinación de unos y otros bienes y el respectivo alcance de tan distinta protección quedó establecido en estos términos:

a) Todos los bienes culturales a que se refiere el artículo 1 de la convención se benefician de una protección general, a la que están sujetas las autoridades del país donde se encuentren. Luego, se necesitará de un acto normativo interno que obligará, ciertamente, a tomar determinadas medidas de salvaguardia y de respeto, y que permitirá al gobierno señalizar el bien o bienes afectados con el emblema de protección.

En este sentido, el alcance de la protección general se dirigirá, en primer lugar, a imponer a la alta parte contratante una obligación de salvaguardia, de forma que se comprometa a preparar, ya en tiempo de paz, el amparo de tal bien, adoptando cuantas medidas resulten necesarias para esto. ${ }^{13}$ Supone, pues, un compromiso estatal de naturaleza preventiva de adoptar medidas legislativas o técnicas para su protección tales como la creación de programas de acción que fomenten la información, la necesaria infraestructura, la financiación o el control de la consecución de su protección por las autoridades nacionales competentes (burocráticas, policía, etcétera). ${ }^{14}$

$\mathrm{Y}$, en segundo lugar, la protección general originará una obligación de respeto que, a su vez, tiene un doble alcance: ${ }^{15}$ primero, para la propia alta parte propietaria en cuanto debe preservarlos de toda posibilidad de 
ataque y, segundo, para la parte adversa en el conflicto a la que se prohíbe atacar los bienes culturales, salvo en los supuestos a los que más adelante nos referiremos. El respeto impone, en definitiva, la obligación de no realizar actos de hostilidad contra los bienes culturales y se extiende, de modo expreso, a la prohibición de represalias contra los bienes culturales. ${ }^{16}$

b) Sólo unos pocos bienes de los comprendidos en el artículo 1o. de la convención podrán gozar de la protección especial, para la cual deben reunir los siguientes requisitos: ${ }^{17}$ ser de "importancia muy grande"; estar alejados de grandes centros industriales o de objetivos militares (salvo que la alta parte signataria de la convención y propietaria del bien afectado se comprometa a no hacer uso alguno del objetivo militar en cuestión y a desviar todo tráfico si se trata de un puerto, estación ferroviaria o aeródromo); no ser utilizado para fines militares $y$, por último, estar inscritos en el Registro Internacional de Bienes Culturales bajo Protección Especial. ${ }^{18}$

El alcance de esta protección especial se despliega desde el momento en que un bien queda inscrito en el Registro Internacional de Bienes Culturales bajo Protección Especial, por lo que afirmamos que este registro presenta el carácter de constitutivo de la protección especial que otorga la Convención de La Haya de 1954. ${ }^{19}$ Desde este momento, pues, debe hacerse efectivo el compromiso adquirido por las altas partes contratantes de "garantizar la inmunidad" de este tipo de bienes. ${ }^{20}$ Los bienes han de ser objeto de salvaguardia y de respeto pero, además, gozarán de inmunidad que tendrá que hacerse efectiva, naturalmente, en paralelo a una conducta adecuada de tal Estado. En este sentido, la violación del compromiso por parte del Estado titular desvincula, a sensu contrario, a la

16 Toman Jirí, op. cit., nota 6, pp. 67-82.

17 Ibidem, pp. 100-104.

18 El Reglamento para la aplicación de la Convención de La Haya de 1954, aprobado al tiempo de ésta y parte integrante de la misma, establece en sus artículos 1 a 16 el procedimiento para la inscripción en el registro. Un procedimiento que se inicia a instancia de parte y en el que son oídas, si así lo desean, las demás altas partes contratantes, las que podrán formular objeciones e, incluso, su oposición a la inscripción. En su caso, la oposición habrá de ser motivada, admitiéndose sólo dos motivos para ello: que no se trate de un bien cultural; o que no reúna los requisitos a los que hemos aludido en texto. Igualmente, en caso de oposición, el expediente podrá concluir en un arbitraje - salvo que expresamente se haya rechazado al iniciarse la controversia-, o en un acuerdo adoptado por mayoría de dos tercios por las altas partes contratantes.

19 Toman, Jirí, op. cit., nota 6, p. 107.

20 Artículo 9o. de la Convención de La Haya de 1954. Ibidem, pp. 138-140. 
parte adversa quien, pese a ello, queda obligada a denunciar la violación antes de tomar cualquier medida contra el bien especialmente protegido. ${ }^{21}$

\section{DIFICULTADES PARA UNA EFECTIVA PROTECCIÓN DE LOS BIENES CULTURALES FRENTE A LOS IMPERATIVOS DE LA GUERRA Y LA DESIDIA ESTATAL}

Expuestas con brevedad las condiciones y el alcance de la protección, la Convención de La Haya de 1954 se enfrenta en primer lugar al arduo problema de la compatibilidad del alcance de su protección con el principio de necesidad militar.

Así, el artículo 4o., párrafo 2o., de la convención declara, respecto de los bienes culturales sujetos a protección general, que las obligaciones derivadas del "respeto" "no podrán dejar de cumplirse más que en el caso de que una necesidad militar impida de manera imperativa su cumplimiento". Y, una disposición similar aparece en el artículo 11, párrafo 2o., respecto de los bienes culturales sujetos a protección especial. Cierto es que hay una diferencia entre ambos preceptos: mientras que en el artículo 4o., párrafo 2o., no aparece determinada la persona que debe apreciar la existencia de la necesidad militar imperiosa, en el artículo 11, párrafo 2o., se concreta que la necesidad militar de atacar bienes culturales bajo protección especial sólo podrá declararse por un jefe militar de unidad igual o superior a una división. ${ }^{22}$

No es el momento de detenernos en una examen exhaustivo de los problemas que plantea el principio de necesidad militar con su correlativo de proporcionalidad; más aún, cuando esta cuestión se desarrolle posteriormente y, en especial, en la segunda parte de este análisis. No obstante, sí nos parece de importancia subrayar que en el proyecto preparado por la UNESCO ya aparecían las cláusulas de necesidad militar, que fueron incluidas pese a la oposición de un grupo importante de países. ${ }^{23} \mathrm{De}$ modo especial, hubo oposición a la exclusión de la inmunidad respecto a los bienes de especial protección, sin que se consiguiera otra cosa que el

21 Ibidem, p. 135.

22 Paniagua Redondo, Ramón, "Regulación jurídico internacional de los bienes culturales en caso de conflicto armado: la Convención de La Haya de 14 de mayo de 1954", Iuris Quaderns de Política Jurídica, núm. 1, 1994, p. 410.

23 Toman, Jirí, op. cit., nota 6, pp. 74-79. 
párrafo 2o. del artículo 11 en su definitiva redacción transaccional, ${ }^{24}$ que exige la necesidad militar ineludible; su declaración expresa por un jefe de nivel división, al menos; $y$, en cuanto las circunstancias lo permitan, la notificación a la parte adversa. Si no se pudiera hacer esta notificación, habrá de hacerla, en todo caso y en el plazo más breve posible, al comisario general de Bienes Culturales de la UNESCO.

Además, hay tres cuestiones de la Convención de La Haya de 1954 que nos son de interés para observar la problemática que conlleva su aplicación, en particular y paradójicamente en tiempos de paz: las medidas de salvaguardia necesarias y obligatorias, entre éstas, la catalogación y la señalización de los bienes; la difusión de su contenido; y el tema de las sanciones por las posibles infracciones.

Respecto a la catalogación y señalización de los bienes, hay que empezar por decir que, desafortunadamente, el sistema de catalogación ha tenido un éxito casi nulo. Sólo se han inscrito en el Registro Internacional de Bienes Culturales bajo Protección Especial un centro monumental y ocho refugios y, es más, algunos de éstos han sido ya retirados de la lista. ${ }^{25}$ Podemos señalar algunas razones que explican este reducido número de bienes inscritos. La primera se centra en el hecho de que para el ingreso en la lista se exija que el bien cultural se encuentre a suficiente distancia de un gran centro industrial o de cualquier objetivo militar, ${ }^{26} \mathrm{y}$ - seguro que conocemos multitud de casos - muchos bienes culturales valiosos se encuentran ubicados en el corazón de ciudades rodeadas de objetivos militares potenciales o, incluso, en su propio seno se encuentran instalaciones o centros de carácter militar. En segundo lugar, otro motivo sería que los Estados puedan objetar el ingreso al registro y en la práctica así lo han hecho, argumentando motivos de variada índole, tales como que la autoridad solicitante no era el representante. ${ }^{27} \mathrm{Y}$, finalmente, en lo tocante a la señalización, el cumplimiento de esta obligación

24 Ibidem, pp. 144-147.

25 Se trata de la Ciudad del Vaticano (18 de enero de 1960); un refugio en Alt-Aussee en Austria (17 de noviembre de 1967); seis refugios en los Países Bajos —Zandvoort (2), Heemskerk (2, cancelados el 22 de septiembre de 1994), Steenwijherwold (cancelado el 22 de septiembre de 1994) y Maastricht (12 de mayo de 1969)_- y el refugio central Oberrieder Stollen en Alemania (22 de abril de 1978). Véase Registro Internacional de Bienes Culturales bajo Protección Especial, UNESCO, Doc. CLT-97/WS/12, agosto de 1997.

26 Véase artículo 8o., párrafo 1o., apartado a), de la Convención de La Haya de 1954.

27 Véase Proyecto de Segundo Protocolo a la Convención de La Haya de 1954 para la Protección de los Bienes Culturales en caso de Conflicto Armado, UNESCO Doc. HC/1999/rev.1, febrero de 1999. 
tampoco ha sido muy efectivo en la práctica estatal, ya que si bien unos pocos Estados están realizando preparativos para su consecución, ${ }^{28}$ otros en cambio se oponen a su señalización argumentando que esto supondría indicar al enemigo el lugar de eventuales "blancos". ${ }^{29}$

En atención a la difusión del contenido de la Convención de 1954, tampoco se auguran mejores expectativas relativas a su cumplimiento a nivel estatal. Así pues, todas o casi todas las altas partes contratantes ignoran la obligación que les impone los artículos 7 y 25 de la convención cuando disponen la difusión "lo más ampliamente posible en sus respectivos países, tanto en tiempo de paz como en tiempo de conflicto armado el texto de la presente convención y del reglamento para su aplicación". Los mismos artículos, además, subrayan la especial trascendencia de la introducción de su estudio en los programas de instrucción militar y de su conocimiento y respeto por los miembros de las fuerzas armadas y, a ser posible, en los de instrucción cívica. ${ }^{30} \mathrm{Al}$ respecto tenemos que comentar que, en los últimos tiempos, la práctica estatal demuestra que se están haciendo importantes esfuerzos para dar cumplimiento a esta obligación de difusión y enseñanza. ${ }^{31}$

Finalmente, en cuanto al problema de las sanciones por las posibles infracciones cometidas, la Convención de La Haya de 1954 ha seguido el mismo sistema establecido en las Convenciones de Ginebra de 1949, ${ }^{32}$ imponiendo a los Estados signatarios la obligación de tomar, dentro de

28 En este sentido, Alemania, Bielorrusia, Croacia, Egipto, Eslovenia, Madagascar, Malasia y Suiza, UNESCO, Information on the Implementation of the Convention for the Protection of Cultural Property in the Event of Armed Conflict, The Hague, 1954, 1995 Reports, Doc. Ref. CLT-95/WS/13, diciembre de 1995, pp. 17, 22-24, 36-37, 42 y 44. La Convención de La Haya de 1954 ha establecido un emblema consistente en un escudo en punta, partido en aspa de color azul ultramar y blanco. Este escudo se utilizará para la protección de bienes culturales y se usará repetido tres veces para los bienes sujetos a protección especial. También puede utilizarse por el personal encargado de su custodia para la tarjeta de identidad de éste y para el transporte de bienes culturales. Véanse artículos 6o., 16 y 17.

29 Así lo indicó Hungría; UNESCO, op. cit., nota anterior, p. 30.

30 Paniagua Redondo, Ramón, op. cit., nota 22, pp. 411 y 412.

31 Toman, Jirí, op. cit., nota 6, pp. 91-96, especialmente véase nota final núm. 3. En este sentido, todos los Estados que han presentado informe ante la UNESCO sobre el cumplimiento de la Convención de La Haya de 1954 subrayan la especial trascendencia de su difusión y enseñanza a los estamentos militares y civiles, que se ha traducido en la realización de cursos de enseñanza, del fomento de reuniones de expertos en la materia y en la publicación de manuales, guías y directrices sobre el tema; véase UNESCO, op. cit., nota 28, pp. 15-48.

32 Toman, Jirí, op. cit., nota 6, p. 293. 
su sistema de derecho penal, las medidas necesarias para castigar con sanciones penales y disciplinarias a los infractores de la convención. ${ }^{33}$

Al respecto, los Estados partes se encuentran obligados a incluir las disposiciones de la convención en sus propios códigos penales y/o códigos penales militares, así como en determinadas regulaciones dirigidas expresamente al estamento militar. ${ }^{34} \mathrm{Al}$ respecto, podemos cuestionarnos si un Estado parte está obligado a perseguir e imponer sanciones penales a personas que hubieren cometido infracciones fuera de la jurisdicción territorial del Estado en cuestión. La respuesta debe ser afirmativa, dado que se trata de uno de los objetivos de la misma convención. Lo que de verdad queda aún por hacer, de acuerdo con el artículo 28 de la convención, sería hacer efectiva sobre la práctica esta facultad estatal de perseguir a aquéllos que han cometido actos criminales fuera de la jurisdicción territorial del Estado parte. ${ }^{35}$

Siguiendo esta línea, deberíamos preguntarnos sobre los avances recientes en el ámbito penal internacional respecto de la protección de los bienes culturales. De esta suerte, el Estatuto del Tribunal Penal Internacional para la ex Yugoslavia de 1993 se refiere expressis verbis a las Convenciones de Ginebra de 1949 y no, sin embargo, a la Convención de La Haya de 1954. No obstante, los actos contra la integridad de los bienes culturales se incluyen en el artículo 3, párrafo d), del Estatuto como "Violación de las leyes o usos de la guerra", de esta forma: "La aprobación o destrucción de instituciones consagradas al culto religioso, la beneficencia y la educación o a las artes y las ciencias, monumentos históricos u obras de arte y científicas, o los daños deliberados a éstos".

33 Artículo 28 de la Convención de La Haya de 1954.

34 Paniagua Redondo, Ramón, op. cit., nota 22, pp. 412 y 413.

35 Toman, Jirí, op. cit., nota 6, p. 294. Sólo Bélgica, Eslovenia y México han informado a la UNESCO que han incorporado a sus códigos penales y/o códigos penales militares disposiciones relativas a la protección de los bienes culturales en periodo de conflicto armado en consonancia con la Convención de La Haya de 1954. No sabemos, pues, si el resto de los Estados que han informado en este sentido han omitido esta cuestión porque efectivamente ya las tienen incorporadas o, por el contrario, aún no lo han hecho. Por otro lado, es importante destacar que el Código Penal de la República de Eslovenia recoge como crimen contra la humanidad y el derecho internacional la destrucción durante periodo de conflicto armado de monumentos culturales e históricos, así como de lugares naturales u otros recursos naturales protegidos y considerados como patrimonio cultural y espiritual o como patrimonio natural. Así, se convierte quizás en el código penal nacional (del que tengamos noticia, claro está) más progresista al calificar esa violación como crimen contra la humanidad y, por otro lado, al incluir a los bienes naturales calificados como patrimonio natural bajo esta singular protección. Véase, UNESCO, op. cit., nota 28, pp. 19, 37 y 42. 
Se observa que los autores del estatuto quisieron recoger las normas consuetudinarias del derecho internacional humanitario aplicadas desde la época del Tribunal de Nüremberg tal y como rezaban en las convenciones de 1907. Pero, como hemos dicho antes, no se toma en consideración a la Convención de La Haya de 1954. Hay autores que no comentan con extrañeza este "olvido"; 36 no obstante, deberíamos preguntarnos su por qué. En efecto, bien pudiera haber recogido el artículo 3, apartado d), del estatuto la definición más completa de "bienes culturales" ofrecida por la Convención de la Haya de 1954 en su artículo 1.

Por otra parte, también nos extraña que el Estatuto de la Corte Penal Internacional de 1998 en su artículo 8o., bajo el título "Crímenes de guerra”, en su párrafo 2o., apartado IX), mantenga el mismo talante anterior cuando entiende por "crimen de guerra": "Dirigir intencionalmente ataques contra espacios dedicados al culto religioso, las artes, las ciencias o la beneficencia, los monumentos, los hospitales y los lugares en que se agrupa a enfermos y heridos, siempre que no sean objetivos militares".

$\mathrm{E}$, incluso, esta tendencia volvemos a encontrarla en la práctica en el caso contra Pavle Strugar, Miodrag Jokic, Milan Zec y Vladimir Kovacevic ante el Tribunal Penal Internacional para la ex Yugoslavia de 22 de febrero de 2001,37 en el que se acusa a militares de las fuerzas serbias por actos y omisiones cometidos contra las leyes y los usos de la guerra entre el 1o. de octubre y el 31 de diciembre de 1991 en el territorio de la República de Croacia, entre otros, del ataque contra la Ciudad Vieja de Dubrovnik, declarado Patrimonio Común de la Humanidad por la UNESCO en 1979 que, además, se encontraba perfectamente señalizado según la Convención de La Haya de 1954 y no se encontraban objetivos militares dentro o en los alrededores de esa zona. ${ }^{38}$

En efecto, en este caso sin duda se invoca y aplica el artículo 3, apartado b) - relativo a la consideración como crimen de guerra de la devastación no justificada por necesidades militares - y el artículo 3, apartado d) -relativo a la destrucción o daño deliberado contra instituciones consagradas al culto religioso y a monumentos históricos - del Estatuto del Tribunal Penal Internacional para la ex Yugoslavia de 1993. Igualmente, se invoca el artículo 52 del Protocolo Adicional I de 1977 relativo a la

36 Toman, Jirí, op. cit., nota 6, p. 295.

37 ICTY, The Prosecutor of the Tribunal against Pavle Strugar, Miodrag Jokic, Milan Zec y Vladimir Kovacevic, Case No. IT-01-42, 22 February 2001.

38 Véase ibidem, párrs. 28-31 y 42. 
protección general de los bienes de carácter civil. En ningún momento, pues, el fiscal fundamenta su acusación sobre la base jurídica de la Convención de La Haya de 1954 y, tampoco, del artículo 53 del Protocolo Adicional I de 1977 relativo a la Protección de los Bienes Culturales y de los Lugares de Culto que, además, hace referencia expresa a la misma Convención de La Haya de 1954 y a otros instrumentos internacionales sobre la materia aplicables.

Con el objetivo de controlar la efectividad del cumplimiento de las disposiciones de la Convención de La Haya de 1954 y, en concreto, respecto de aquéllas referidas a los últimos aspectos señalados que, sin lugar a duda, necesitan de una certera voluntad estatal para su puesta en práctica, la misma convención dispone en su artículo 26, párrafo 2o. que:

[Las altas partes contratantes], además, dirigirán al director general, por lo menos una vez cada cuatro años, informes en los que figuren los datos que estimen oportunos sobre las medidas tomadas, preparadas o estudiadas por sus respectivas administraciones para el cumplimiento de la presente convención y del reglamento para la aplicación de la misma.

Nos encontramos, pues, ante un mecanismo de control internacional del cumplimiento por parte de los Estados de las disposiciones de un tratado internacional basado en el sistema del envío de informes periódicos. Este mecanismo no contencioso de control internacional ha tenido un cierto éxito en aquellos convenios relativos a la protección internacional de los derechos humanos. ${ }^{39}$ No obstante, fuera de este ámbito, produce extrañeza su adopción en un tratado relativo a derecho internacional humanitario y, aún en mayor medida, en época tan temprana (1954), debido a las conocidas reticencias de los Estados a adoptar algún mecanismo de control sobre su conducta en materia de aplicación interna de las normas internacionales establecidas en el tratado respectivo, aunque se trate de un sistema de control muy tenue que evita, sobre todo, la confrontación o

39 Nos referimos a la Convención Internacional para la Eliminación de todas las Formas de Discriminación Racial de 1965; el Pacto Internacional de Derechos Económicos, Sociales y Culturales de 1966; el Pacto Internacional de Derechos Civiles y Políticos de 1966; la Convención Internacional sobre la Represión y el Castigo del Crimen de Apartheid de 1973; la Convención sobre Eliminación de todas las formas de Discriminación contra la Mujer de 1979; la Convención contra la Tortura y otros Tratos o Penas Crueles, Inhumanos o Degradantes de 1984; la Convención Internacional contra el Apartheid en los Deportes de 1985; y, por último, la Convención sobre los Derechos del Niño de 1989. 
la acusación a los gobiernos por presuntas violaciones de las obligaciones internacionales que han asumido ya que no son, en su origen, mecanismos contenciosos ni contradictorios.

Efectivamente, la obligación de informar supone, en principio, un procedimiento obligatorio no sujeto a reservas o derogaciones por parte de los Estados que deseen ser partes en el tratado respectivo; en segundo lugar, conlleva la creación de un órgano de control establecido para recibir esos informes periódicos que dará lugar al inicio de un procedimiento no jurisdiccional de examen de los mencionados informes que terminará en unas "observaciones finales" — donde se incluyen los aspectos positivos y negativos que el órgano instituido al efecto haya encontrado en su estudio, así como sus conclusiones y recomendaciones para superar los problemas más importantes que el mencionado órgano haya encontrado- que carecen de valor obligatorio; y, por último, la posterior publicación y difusión de tales opiniones en los informes anuales de los distintos órganos de control, cuya única virtud radica en ejercer cierta presión moral sobre los Estados.

La práctica estatal respecto del envío de informes periódicos relativos al cumplimiento efectivo de la Convención de La Haya de 1954 siempre ha sido decepcionante (sólo alrededor del 20\% de los Estados partes han cumplido alguna vez con esta obligación) y, cuando se ha hecho, no siempre se han ajustado a una exposición rigurosa de las medidas tomadas en cumplimiento de cada una de las disposiciones de la convención y, menos aún, respecto de aquellas medidas adoptadas cuando el Estado parte se ha encontrado inmerso en un conflicto armado. ${ }^{40}$ Es más, según estudios realizados recientemente, el número de "Estados cumplidores" (23) no había aumentado proporcionalmente al entonces número de ratificaciones (105). ${ }^{41}$ No obstante, no toda la falta de diligencia a este respecto recae en manos estatales puesto que, hasta abril de 2002, el último informe-resumen de la UNESCO sobre la evaluación de los informes estatales data de 1995, previéndose que aquél esté preparado para 2004

40 Toman, Jirí, op. cit., nota 6, pp. 280-282.

41 Hladik, Jan, "Reporting system under the 1954 Convention for the Protection of Cultural Property in the Event of Armed Conflict", International Review of the Red Cross, vol. 82, núm. 840, diciembre de 2000, p. 1008. 
(¡ocho años de diferencia entre cada evaluación del cumplimiento de la convención efectuada por la organización!).42

Avanzando en el tiempo y en busca de una protección de los bienes culturales más perfecta, el artículo 53 del Protocolo Adicional I de 1977, dejando a salvo todas las prescripciones de la Convención de La Haya de 1954, prohíbe:

a) Cometer actos de hostilidad dirigidos contra los monumentos históricos, obras de arte o lugares de culto que constituyen el patrimonio cultural o espiritual de los pueblos.

b) Utilizar tales bienes en apoyo del esfuerzo militar.

c) Hacer objeto de represalias tales bienes.

Simplificadamente, se contiene un precepto similar en el artículo 16 del Protocolo Adicional II de 1977 que no habla, sin embargo, de la prohibición de las represalias.

La finalidad primordial de estos preceptos era la de conseguir que los bienes culturales bajo protección especial a los que se refería el artículo 8o. de la Convención de La Haya de 1954 quedasen protegidos siempre, sin necesidad de la previa inscripción y con respecto a todos los Estados que no eran parte en dicha convención..$^{43}$ Lo que no es posible determinar es la efectividad de tal propósito, dadas las reticencias que plantearon para la ratificación de los protocolos adicionales de 1977 los mismos Estados que encontraron obstáculos para la ratificación de la Convención de La Haya de $1954 .{ }^{44}$

No obstante, la innovación más importante de los protocolos adicionales de 1977 respecto a la Protección de los Bienes Culturales se centró en definir como infracción grave:

42 Información obtenida a través del señor Jan Hladik mediante correo de fecha 24 de octubre de 2003.

43 Bothe, Michael et al., New Rules for Victims of Armed Conflicts. Commentary on the Two 1977 Protocols Additional to the Geneva Conventions of 1949, Martinus Nijhoff Publishers, 1982, pp. 333 y 334; Sandoz, Yves et al. (eds.), Commentaire des Protocoles Additionnels du 8 juin 1977 aux Conventions de Genève du 12 août 1949, Comité International de la Croix-Rouge, Martinus Nijhoff Publishers, 1986, p. 659; Toman, Jirí, op. cit., nota 6, pp. 388 y 394-395.

44 No obstante, quede aquí constancia del esfuerzo hecho por numerosos Estados entre los que hemos de destacar a España que en 1954 se opuso con tenacidad a la inclusión de las cláusulas de excepción (artículos 4o., párrafo 2o., y 11, párrafo 2o. Convención de La Haya de 1954) y que, en 1977, promovió - junto con Grecia y Jordania - de la enmienda que dio lugar al artículo 53 del Protocolo Adicional I y al artículo 16 del Protocolo Adicional II. Véase Toman, Jirí, op. cit., nota 6, pp. 76 y 382 ; y CDDH/III/17/Rev. 1; XV Official Records, p. 213. 
El hecho de dirigir un ataque a monumentos históricos, obras de arte o lugares de culto claramente reconocidos que constituyen el patrimonio cultural o espiritual de los pueblos y a los que se haya conferido protección especial en virtud de acuerdos especiales celebrados, por ejemplo, dentro del marco de una organización internacional competente, causando como consecuencia extensas destrucciones de los mismos, cuando no haya pruebas de violación por la parte adversa del apartado b) del artículo 53 y cuando tales monumentos históricos, lugares de culto y obras de arte no estén situados en la inmediata proximidad de objetivos militares. ${ }^{45}$

Aunque, bien es cierto, que de una forma un tanto complicada y con importantes dudas en cuanto a su interpretación. ${ }^{46}$

Con el fin de completar este iter jurídico relativo a la protección del patrimonio cultural, es preciso referirnos brevemente al Protocolo II sobre Prohibiciones o Restricciones del Empleo de Minas, Armas Trampa y otros Artefactos, según fue enmendado en 1996 antes mencionado que ampara los bienes culturales, en primer lugar, de manera indirecta al prohibir en general el empleo de armas trampa contra "emblemas, signos o señales protectoras reconocidos internacionalmente"; $47 \mathrm{y}$, en segundo lugar, de manera directa al prohibir expresamente el empleo de armas trampa y otros artefactos contra los "monumentos históricos, obras de arte o lugares de culto que constituyan el patrimonio cultural o espiritual de los pueblos". ${ }^{48}$ En cuanto al Protocolo III sobre Prohibiciones o Restricciones del Empleo de Armas Incendiarias de 1980, la Protección de los Bienes Culturales no se contempla de forma específica, aunque podríamos incluirla dentro de la protección más genérica referida a la protección de los "bienes de carácter civil". ${ }^{49}$

45 Artículo 85, párrafo 4o., apartado d), del Protocolo Adicional I de 1977.

46 Véase, al respecto, Bothe, Michael et al., op. cit., nota 43, pp. 519-520; Sandoz, Yves et al. (eds.), op. cit, nota 43, pp. 657-667, en concreto pp. 1026 y 1027; Toman, Jirí, op. cit., nota 6, pp. 391-393.

47 Artículo 7, párrafo 1o., apartado a) del Protocolo II, según fue enmendado en 1996.

48 Artículo 7, párrafo 1o., apartado i) del Protocolo II, según fue enmendado en 1996.

49 Artículo 2, párrafos 1o. y 3o. del Protocolo III de 1980. 


\section{A LA BÚSQUEDA DE UN BLINDAJE MÁS PERFECTO. EL SEGUNDO PROTOCOLO ADICIONAL DE 1999}

La eficacia de la Convención de La Haya de 1954 se convirtió en materia de preocupación internacional a comienzos de los años noventa del pasado siglo, en particular tras el ataque a la ciudad de Dubrovnik en 1991 durante el conflicto de la antigua Yugoslavia al que nos hemos referido anteriormente. Estos hechos conmovieron a la opinión pública internacional y el gobierno de los Países Bajos, como parte de su contribución al Decenio de las Naciones Unidas sobre el Derecho Internacional, decidió promover una revisión de la Convención de La Haya de 1954. Como resultado, los Países Bajos y la UNESCO conjuntamente encargaron y financiaron un estudio sobre la revisión de los objetivos y el funcionamiento de la convención y del protocolo, con la finalidad de identificar medidas para mejorar su aplicación y eficacia, y definir si sería o no necesaria una revisión de la convención mediante, quizás, un protocolo adicional a la misma. ${ }^{50}$

A este primer paso siguieron varias reuniones de expertos y posteriores propuestas hasta llegar a un proyecto final de un Segundo Protocolo a la Convención de La Haya de 1954. ${ }^{51}$ La Conferencia Diplomática para la elaboración del Segundo Protocolo a la Convención de La Haya de 1954 se celebró en La Haya del 15 al 26 de marzo de 1999. El 26 de marzo de 1999, la conferencia aprobó por consenso el Segundo Protocolo a la Convención de La Haya de 1954. ${ }^{52}$

Este Segundo Protocolo a la Convención de La Haya de 1954 es adicional a la misma convención, de forma que no la modifica en modo alguno, sino que la complementa y es aplicable únicamente a los Estados

50 El resultado fue un estudio realizado por el profesor Boylan, Patrick, Review of the Convention for the Protection of Cultural Property in the Event of Armed Conflict (The Hague Convention of 1954), UNESCO Doc. Ref. CLT.93/WS/12, 1993, 248 pp.

51 Sobre este proceso, véase Henckaerts, Jean-Marie, "New rules for the protection of cultural property in armed conflict. The significance of the Second Protocol to the 1954 Hague Convention for the Protection of Cultural Property in the Event of Armed Conflict", International Review of the Red Cross, vol. 81, núm. 835, septiembre de 1999, pp. 594 y 595. Igualmente, véase UNESCO Doc. HC/1999/1/rev.1, February 1999, Draft Second Protocol to the Hague Convention of 1954 for the Protection of Cultural Property in the Event of Armed Conflict.

52 UNESCO Doc. HC/1999/7, 26 de marzo de 1999, Second Protocol to the Hague Convention of 1954 for the Protection of Cultural Property in the Event of Armed Conflict, signed at the Hague, 17 de mayo de 1999. 
que la hayan ratificado. ${ }^{53}$ Podemos estimar como principales innovaciones de este Segundo Protocolo de 1999 en relación con la Convención de La Haya de 1954 los siguientes cuatro puntos:

a) En cuanto a su ámbito de aplicación, el Segundo Protocolo de 1999 se aplica a conflictos armados tanto internacionales como no internacionales. ${ }^{54}$ De esta manera, la extensión de su aplicación a los conflictos armados no internacionales ha supuesto un loable acomodamiento a los tiempos presentes, en los que la mayoría de los conflictos armados son de carácter no internacional y en los que, por otra parte, se ha demostrado que la protección de los bienes culturales puede ser problemática. ${ }^{55}$

Por otro lado, la extensión de su ámbito de aplicación a los conflictos de carácter no internacional se adelanta a las disposiciones que el Protocolo Adicional I de 1977 señala respecto a su sistema de represión penal, que sólo se aplica a los conflictos armados internacionales. Igualmente, es importante señalar que esta tendencia también es conforme con las disposiciones del Estatuto de Roma de 1998 en el que la Corte Penal Internacional tiene jurisdicción sobre los crímenes de guerra cometidos contra bienes culturales tanto en los conflictos armados internacionales como en los no internacionales, como veremos posteriormente

b) El Segundo Protocolo de 1999 prescribe mejores orientaciones respecto a las medidas de salvaguardia que los Estados deben tomar en tiempo de paz contra los efectos devastadores de eventuales hostilidades, que ya recogía el artículo 3o. de la Convención de La Haya de 1954. Esta mejora radica en suministrar ejemplos concretos de medidas que deben tomarse en tiempo de paz, a saber: ${ }^{56}$ la preparación de inventarios; la planificación de medidas de emergencia; la preparación para un eventual traslado; y la designación de autoridades competentes que se responsabilicen de la salvaguarda de los bienes culturales. Con la intención de brindar ayuda financiera o de otra índole en apoyo a estas medidas preparato-

53 Véase artículo 2 del Segundo Protocolo de 1999. El 24 de mayo de 2004, de los 110 Estados partes en la Convención de La Haya de 1954, había un total de 22 Estados que habían ratificado o se habían adherido al Segundo Protocolo de 1999. Así pues, este Segundo Protocolo de 1999 se encuentra en vigor desde el 9 de marzo de 2004 en atención a lo dispuesto en su artículo 43, párrafo 1o.; Eslovenia fue el último Estado en acceder el 13 de abril de 2004. Estos Estados son: Argentina, Austria, Azerbaiján, Bielorrusia, Bulgaria, Chipre, Costa Rica, El Salvador, Eslovaquia, Eslovenia, España, Gabón, Guinea Ecuatorial, Honduras, Libia, Lituania, México, Nicaragua, Panamá, Qatar, antigua República Yugoslava de Macedonia y, por último, Serbia y Montenegro.

54 Artículos 3o. y 22 del Segundo Protocolo de 1999.

55 Henckaerts, Jean-Marie, op. cit., nota 51, pp. 617 y 618.

56 Artículo 5o. del Segundo Protocolo de 1999. 
rias, se dispone la creación de un Fondo para la Protección de los Bienes Culturales en Caso de Conflicto Armado, ${ }^{57}$ que será administrado por un Comité para la Protección de los Bienes Culturales en Caso de Conflicto Armado. ${ }^{58}$

Por otro lado, llama nuestra atención el hecho de que este Segundo Protocolo de 1999 amplíe la disposición general relativa a la "difusión" ya contenida en la Convención de La Haya de 1954. ${ }^{59}$ Quizás se pretenda con ello paliar la falta de voluntad estatal a este respecto, como hemos comprobado anteriormente.

En este sentido, se encomienda a las autoridades militares y civiles que asumen responsabilidades respecto a la aplicación del Segundo Protocolo que estén perfectamente familiarizadas con el mismo. Especialmente, se solicita la incorporación a los reglamentos militares de orientaciones e instrucciones relativas a la protección de los bienes culturales ${ }^{60}$ e, igualmente, se insta a crear mejores lazos de cooperación entre los Estados, la UNESCO y las organizaciones gubernamentales y no gubernamentales pertinentes en la materia. ${ }^{61}$

c) En cuanto a la obligación de respeto por los bienes culturales, el Segundo Protocolo de 1999 da un nuevo contenido a la noción de "necesidad militar imperativa" dispuesta en la Convención de La Haya de $1954,{ }^{62}$ con la intención de ampliar su significado y sus efectos en atención a su acomodamiento a lo dispuesto en el Protocolo Adicional I de 1977 respecto a la definición de "objetivo militar". ${ }^{63}$ Además, esta noción se ha confirmado que forma parte del derecho internacional consuetudinario, como lo ha demostrado el hecho de que países como Estados Unidos de América, Turquía e India, que no son Estados partes del Protocolo Adicional I de 1977, lo hayan declarado así durante la Conferencia Diplomática de 1999 que suscribió el Segundo Protocolo de 1999. ${ }^{64}$

A continuación pues, merece la pena detenernos en el análisis del importante e innovador artículo 6o. del Segundo Protocolo de 1999 que 
delimita y condiciona el concepto de "necesidad militar" en atención a la noción de "objetivo militar" de la siguiente manera:

A fin de garantizar el respeto de los bienes culturales de conformidad con el artículo 4o. de la convención:

a) Una derogación fundada de una necesidad militar imperativa conforme al párrafo 2o. del artículo 4o. de la convención sólo se podrá invocar para dirigir un acto de hostilidad contra un bien cultural cuando y durante todo el tiempo en que:

i) ese bien cultural, por su función, haya sido transformado en un objetivo militar; y

ii) no exista otra alternativa prácticamente posible para obtener una ventaja militar equivalente a la que ofrece el hecho de dirigir un acto de hostilidad contra ese objetivo;

b) Una derogación fundada en una necesidad militar imperativa conforme al párrafo 2o. del artículo 4o. de la convención sólo se podrá invocar para utilizar bienes culturales con una finalidad que pueda exponerles a la destrucción o al deterioro cuando y durante todo el tiempo en que resulte imposible elegir entre esa utilización de los bienes culturales y otro método factible para obtener una ventaja militar equivalente;

c) La decisión de invocar una necesidad militar imperativa solamente será tomada por el oficial que mande una fuerza de dimensión igual o superior a la de un batallón, o de menor dimensión cuando las circunstancias no permitan actuar de otra manera;

d) En caso de ataque basado en una decisión tomada de conformidad con el apartado a) se debe dar aviso con la debida antelación y por medios eficaces, siempre y cuando las circunstancias lo permitan.

En primer lugar, hay que destacar que el Segundo Protocolo de 1999 recoge el mismo concepto de "objetivo militar" que el señalado en el Protocolo Adicional I de 1977. ${ }^{65}$ Observamos pues, que la noción de "objetivo militar" como tal incorpora la idea de necesidad militar y, de esta forma, una vez que un bien adquiere el carácter de "objetivo militar" puede ser destruido, capturado o neutralizado, salvo en ciertos casos excepcionales. En nuestro caso, la protección ofrecida a los bienes cultu-

65 Artículo 52, párrafo 2o., del Protocolo Adicional de 1977, y artículo 1, apartado f), del Segundo Protocolo de 1999: "Por 'objetivo militar' se entenderá un objeto que por su naturaleza, ubicación, finalidad o utilización, contribuye eficazmente a la acción militar y cuya destrucción total o parcial, captura o neutralización ofrece en las circunstancias del caso una ventaja militar definida". 
rales es mayor desde el momento en que el concepto de "objetivo militar" se utiliza para definir la excepción de la necesidad militar. ${ }^{66}$

En segundo lugar, el requisito establecido por la Convención de La Haya de 1954 de que la necesidad militar debe ser "imperativa" queda aclarado en el artículo 6o., apartado a), subapartado ii), del Segundo Protocolo de 1999 mediante una segunda condición: "que no exista otra alternativa prácticamente posible". De esta suerte, en contadas ocasiones podrá invocarse la necesidad militar para justificar un ataque a los bienes culturales que obstaculicen el paso de un ejército en avanzada, pues casi siempre existirán otras alternativas para eludir dichos bienes. Además, igualmente esta condición supondrá que cuando se pueda elegir entre varios objetivos militares y uno de ellos es un bien cultural, no deberá atacarse este último. ${ }^{67}$

En tercer lugar, observemos que una derogación de la protección ofrecida a los bienes culturales invocando la excepción de la necesidad militar sólo podrá efectuarse en el caso de "utilizar bienes culturales con una finalidad que pueda exponerles a la destrucción o al deterioro", según reza el artículo 6o. en su apartado b). Además, se establece una condición temporal: "cuando y durante todo el tiempo en que resulte imposible elegir entre esa utilización de los bienes culturales y otro método factible para obtener una ventaja militar equivalente". En definitiva, pues, la "utilización" que se haga de los bienes culturales es lo que determina el que pierdan su protección; interpretación, por otro lado, acorde con la misma, dada para el artículo 53 del Protocolo Adicional I de 1977. ${ }^{68}$ Precisamente, el mismo artículo 6o., apartado a), subapartado i), cuando señala que "sólo se podrá invocar para dirigir un acto de hostilidad contra un bien cultural cuando y durante todo el tiempo en que ese bien cultural, por su función, haya sido transformado en un objetivo militar" se dirige en apoyo de esta idea. ${ }^{69}$

66 Hladik, Jan, "The 1954 Hague Convention for the Protection of Cultural Property in the Event of Armed Conflict and the notion of military necessity. The review of the 1954 Convention and the adoption of the Second Protocol thereto (26 March 1999)", International Review of the Red Cross, vol. 81, núm. 835, septiembre de 1999, p. 629.

67 Así pues, esta disposición incluye los bienes culturales entre los objetivos militares que, de conformidad con el artículo 57, párrafo 3o., del Protocolo Adicional I de 1977, no deberán atacarse. Henckaerts, Jean-Marie, op. cit., nota 51, p. 601.

68 Véase Bothe, Michael et al., op. cit., nota 43, pp. 328-334, en concreto pp. 333 y 334; Sandoz, Yves et al. (eds.), op. cit, nota 43, pp. 657-667, en concreto p. 666.

69 Henckaerts, Jean-Marie, op. cit., nota 51, p. 629. 
Igualmente, el artículo 13 también recoge la excepción de la necesidad militar con las mismas premisas en relación con los bienes culturales bajo protección reforzada, cuyas características veremos a continuación. Sin embargo, en este caso se fortalecen dos requisitos que también encontramos en el artículo 6o. para los bienes bajo protección general: ${ }^{70}$ uno, que el ineludible ataque haya sido ordenado por el nivel más alto del mando operativo (cuando para los bienes bajo protección general se exige que la decisión sea tomada por el oficial que mande una fuerza de dimensión igual o superior a la de un batallón, o de menor dimensión cuando las circunstancias no permitan actuar de otra manera) $; ;^{71} \mathrm{y}$, dos, que se haya dado obligatoriamente aviso con antelación por medios eficaces y, además, un plazo razonable a las fuerzas adversarias para regularizar la situación (cuando para los bienes bajo protección general sólo se exige que se dé aviso con la debida antelación y por medios eficaces, "siempre y cuando las circunstancias lo permitan"). ${ }^{72}$

Por último, la obligación de respeto de los bienes culturales también alcanza al sistema de protección reforzada que el Segundo Protocolo de 1999 establece en su capítulo 3 -artículos 10 a 14-. Con el objetivo de paliar el escaso éxito del sistema de protección especial de la Convención de La Haya de 1954, el Segundo Protocolo de 1999 tiene el acierto de suprimir el criterio de la distancia y de restringir de manera estricta la posibilidad de interponer objeciones. En el nuevo sistema, para que pueda incluirse un bien en la nueva Lista de Bienes Culturales bajo Protección Reforzada, ${ }^{73}$ éste debe cumplir tres requisitos: ${ }^{74}$

a) Que sea un patrimonio cultural de la mayor importancia para la humanidad.

b) Que esté protegido por medidas nacionales adecuadas, jurídicas y administrativas, que reconozcan su valor cultural e histórico excepcional y garanticen su protección en el más alto grado.

c) Que no sea utilizado con fines militares o para proteger instalaciones militares, y que haya sido objeto de una declaración de la parte que lo controla en la que se confirme que no se utilizará para esos fines.

70 Hladik, Jan, op. cit., nota 66, pp. 629 y 630.

71 Artículo 6o., apartado c), del Segundo Protocolo de 1999.

72 Ibidem, artículo 6o., apartado d).

73 Ibidem, artículo 11.

74 Ibidem, artículo 10. 
La decisión de otorgar o denegar la protección reforzada sólo podrá tomarse sobre la base de los criterios antes señalados y, en su caso, las objeciones a la concesión deberán de ser precisas y apoyarse en hechos. ${ }^{75}$

El hecho de que el Segundo Protocolo de 1999 sea adicional a la Convención de La Haya de 1954 y, en ese sentido, no la enmienda, condujo a crear una nueva lista de bienes de protección excepcional a la que, incluso, se le hubo de otorgar otro nombre distinto. Así pues, los Estados cuyos bienes hayan sido registrados en la lista anterior (Lista de Bienes bajo Protección Especial) y ratifiquen el Segundo Protocolo de 1999, deberán solicitar su transferencia a la nueva lista (Lista de Bienes bajo Protección Reforzada). ${ }^{76}$

$\mathrm{Si}$, como se ha dicho, el hecho de que se use ampliamente la Lista de Bienes Patrimonio de la Humanidad, establecida por la Convención sobre Patrimonio Mundial Cultural y Natural de 1972, resultó un incentivo para tratar de hacer funcionar el Registro Internacional de Bienes Culturales bajo Protección Reforzada ${ }^{77}$ (sobre todo, tras el caso de los ataques de las fuerzas serbias contra la ciudad de Dubrovnik en 1991) la cuestión que deberíamos plantearnos es la siguiente: ¿cómo es que en este nuevo Segundo Protocolo de 1999 no se ha considerado la posibilidad de tomar como modelo de referencia el contenido de la Lista de Bienes Patrimonio de la Humanidad para elaborar la Lista de Bienes bajo Protección Reforzada o, lo que es lo mismo, cómo no se han unificado ambas listas? ${ }^{78}$ Esta pregunta surge al ser testigos de que la Lista de Bie-

75 Ibidem, artículo 11, párrafos 5o. y 7o.

76 Henckaerts, Jean-Marie, op. cit., nota 51, p. 609.

77 Incluso, con el objetivo de promover el interés de los Estados partes en la Convención de La Haya de 1954 por dotar a sus bienes culturales de las garantías que otorga la protección especial, el Consejo Consultivo de la UNESCO adoptó, en mayo de 1993, la Decisión 5.5.1. por la que se invitaba a los Estados que sean a la vez partes en la Convención de La Haya y en la Convención sobre Patrimonio Mundial de 1972 y que tengan determinados sitios de interés cultural inscritos en la Lista sobre Patrimonio Mundial, a que se animen a inscribirlos en el Registro Internacional de los Bienes Culturales bajo Protección Especial. Solicitud que no recibió respuesta alguna, véase Hladik, Jan, "Actividades de la UNESCO en materia de aplicación y promoción de la Convención de La Haya de 1954 para la protección de los bienes culturales en caso de conflicto armado y de sus dos protocolos", Protección de los Bienes Culturales en caso de Conflicto Armado, Informe de la Reunión de Expertos (Ginebra, 5-6 de octubre de 2000), CICR - Servicio de Asesoramiento en Derecho Internacional Humanitario-, febrero de 2002, pp. 66 y 67; Henckaerts, Jean-Marie, op. cit., nota 51, pp. 608 y 609.

78 Esta sensata idea ya la había expresado Stanislaw E. Nahlik en 1986, cuando expuso que una futura revisión de la Convención de La Haya de 1954 debería incluir una reforma del artículo 8 de esta convención de acuerdo con los parámetros protectores de la Convención de Patrimonio Mundial de 1972. Es más, esta cuestión se discutió en la 17a. sesión del Comité sobre 
nes Patrimonio de la Humanidad contiene monumentos y lugares nacionales que tienen un "valor universal excepcional"; además, los Estados solicitan el ingreso en esta lista privilegiada de forma constante y profusa, incluso "rivalizando" entre ellos y, si se les otorga, hacen pública la concesión de este título con honores, como veremos en el apartado siguiente. ¿No cabría, pues, mejor registro de bienes que sirviera de pauta para su prevención y protección en periodo de conflicto armado? Como respuesta, se ha dicho que los procedimientos y las condiciones de ambos registros no se ajustaban. ${ }^{79}$ A lo que podemos responder que, viendo el escaso éxito de la anterior Lista de Bienes bajo Protección Especial y los no muy halagüeños presagios para la futura Lista de Bienes bajo Protección Reforzada, queda demostrado que el procedimiento de registro para el caso de conflicto armado es del todo inoperante. ¿Por qué no adaptarnos al eficaz sistema establecido también por la UNESCO para periodo de paz?

Quizás encontremos las respuestas a estas cuestiones si continuamos con la exposición de cuándo el Segundo Protocolo de 1999 considera que un bien cultural que se encuentra bajo protección reforzada pierde tal protección. En un primer momento, podríamos pensar que la pérdida de la protección reforzada está condicionada a que la utilización del bien cultural lo convierta en un objetivo militar.

No obstante, como claramente se ha expuesto, ${ }^{80}$ el Segundo Protocolo de 1999 no establece un sistema de protección más bajo o más alto según que el tipo de protección sea general o reforzada. No existe diferencia en el nivel de protección y no hace falta distinguir dos formas distintas en que un bien cultural pueda convertirse en un objetivo militar.

Patrimonio Mundial (junio, 1992) y de acuerdo con esto se incluyó una nueva disposición en el texto revisado de las directrices operacionales para el cumplimiento de la Convención sobre Patrimonio Mundial adoptado por este órgano en 1993. Esta nueva disposición reconoce la importancia de la relación entre la Convención de Patrimonio Mundial de 1972 y las Convenciones de Ginebra de 1949, la Convención de La Haya de 1954, la Convención de la UNESCO de 1970, la Convención de Ramsar relativa a los Humedales de Importancia Internacional de 1971, la Convención sobre el Comercio Internacional de Especies Amenazadas de Flora y Fauna Silvestres (CITES) de 1973, así como otros tratados o futuros tratados que persigan como objetivo la conservación y preservación medioambiental. No obstante, esta nueva disposición sólo insta a los órganos intergubernamentales de control de tales convenciones a llegar a una apropiada coordinación y al intercambio de información entre ellos. Véase respecto de esta cuestión, Toman, Jirí, op. cit., nota 6, pp. 117 y 118, especialmente nota final núm. 5, y p. 375.

79 Henckaerts, Jean-Marie, op. cit., nota 51, p. 608.

80 Ibidem, pp. 609-611. 
La diferencia entre ambos tipos de protección reside en las obligaciones del titular del bien cultural. De tal forma, en el caso de la protección general, el titular del bien tiene derecho, si es necesario, a convertir el bien en objetivo militar utilizándolo para una acción militar. En el caso de la protección reforzada, el titular del bien nunca tiene derecho a convertir el bien en objetivo militar utilizándolo para una acción militar. Así que, para poder registrar un bien en la Lista de Bienes bajo Protección Reforzada se requiere que el Estado parte se cuestione sin dudas si alguna vez necesitará dicho bien para fines militares y obtenga una respuesta negativa. Y lo que es más importante, en este caso la utilización con fines militares de un bien incluido en la Lista de Bienes bajo Protección Reforzada equivaldría a una violación grave del Segundo Protocolo de 1999 y el Estado titular del bien e infractor estaría sujeto a una sanción penal como criminal de guerra, como veremos en el siguiente punto d).

En efecto, la terminología "protección reforzada" induce a error; más bien, el sistema debería denominarse de "protección registrada" o "certificada", en el sentido de que el titular del bien registra o certifica su compromiso de que el bien nunca se utilizará con fines militares.

Comprobamos así que la omisión de esa unificación de listas que solicitábamos anteriormente era, sin dudas, una omisión consentida, que no fruto del olvido. ¿Cómo un Estado accedería a que los bienes culturales que tiene registrados en la Lista de Bienes Patrimonio de la Humanidad vía Convención sobre Patrimonio Mundial de 1972, pasen a formar parte de forma automática a la Lista de Bienes bajo Protección Reforzada vía Segundo Protocolo de 1999? ¿Cómo certificar su promesa de que todos esos bienes no se utilizarán para contribuir a la acción militar? Sin lugar a dudas, pues, nos aventuramos a presagiar que la inoperancia del nuevo registro establecido por el Segundo Protocolo de 1999 para una clase de bienes que, en puridad, ya se encuentran registrados, será fruto de una ("muy sabia") falta de voluntad estatal, más que de simples excusas basadas en un complejo ajuste procedimental entre registros, en dificultades técnicas de ubicación o de temores a eventuales atentados.

d) Por último, en este Segundo Protocolo de 1999 se ha dado un gran paso respecto al importante tema de la responsabilidad penal por las eventuales violaciones de su normativa. Este es, quizás, el ámbito en el que el Segundo Protocolo de 1999 aclara y desarrolla el derecho interna- 
cional humanitario en relación con la protección de los bienes culturales en periodo de conflicto armado. ${ }^{81}$

Así, en primer lugar, el artículo 15 - elaborado a partir de las disposiciones contenidas en el Protocolo Adicional I de 1977 y en el Estatuto de la Corte Penal Internacional de 1998 — 82 define cinco actos que constituyen violaciones graves que exigen una sanción penal si se cometen de manera intencional y en violación de la Convención de La Haya de 1954 o de su Segundo Protocolo de 1999, a saber:

1) Hacer objeto de un ataque a un bien cultural bajo protección reforzada.

2) Utilizar los bienes culturales bajo protección reforzada o sus alrededores inmediatos en apoyo de acciones militares.

3) Causar destrucciones importantes en los bienes culturales protegidos por la convención y el Segundo Protocolo o apropiárselos a gran escala.

3) Hacer objeto de un ataque a un bien cultural protegido por la convención o por el Segundo Protocolo.

4) Por último, robar, saquear o hacer un uso indebido de los bienes culturales protegidos por la convención, y perpetrar actos de vandalismo contra ellos.

Esta lista de violaciones graves está basada en propuestas presentadas por Austria y el Comité Internacional de la Cruz Roja, lo que explica por qué contiene dos tipos de violaciones. ${ }^{83}$

El primer grupo propuesto por Austria comprendería las tres primeras violaciones señaladas - a) a c) — que son aquéllas que en las Convenciones de Ginebra de 1949 y en el Protocolo Adicional I de 1977 se denominan "infracciones graves". ${ }^{84}$ Respecto de éstas, los artículos 17 a 20 del Segundo Protocolo de 1999 establece un sistema coherente de enjuiciamiento y de extradición del delincuente desde el punto de vista del derecho penal internacional. De esta forma, los Estados deberán ejercer su competencia sobre la base de la jurisdicción penal universal, es decir, que deberán ejercer su competencia para enjuiciar no sólo cuando la infracción se comete en territorio nacional o cuando el inculpado sea un

81 Véase artículo 28 de la Convención de La Haya de 1954.

82 Artículo 53 del Protocolo Adicional I de 1977, y artículo 8o., párrafo 2o., apartado b), subapartado IX), del Estatuto de la Corte Penal Internacional de 1998.

83 Henckaerts, Jean-Marie, op. cit., nota 51, p. 615.

84 Artículo 85, párrafo 4o., apartado d) del Protocolo Adicional I de 1977. 
nacional, sino también cuando es un no nacional el que comete la infracción. ${ }^{85}$ No obstante, existe una excepción respecto de los nacionales de los Estados que no son partes en el Segundo Protocolo de 1999, que se incorporó al texto a propuesta de un conocido Estado tradicionalmente protector de sus nacionales. ${ }^{86}$ Sin embargo, el alcance de esta excepción disminuye con el reconocimiento en el mismo Segundo Protocolo de 1999 de que, en virtud del derecho nacional e internacional aplicable -incluido el derecho internacional consuetudinario-, los Estados pueden ejercer jurisdicción sobre dichas personas. ${ }^{87}$

El segundo grupo comprendería las dos últimas violaciones graves de la lista - d) y e) - , añadidas a propuesta del Comité Internacional de la Cruz Roja sobre la base de lo dispuesto en el Estatuto de la Corte Penal Internacional de 1998 que recogía estos actos como constitutivos de crímenes de guerra sujetos, por ello, a sanción penal. ${ }^{88}$ No obstante, en estos dos casos no existe obligación de ejercer jurisdicción cuando la presunta infracción sea cometida en el extranjero por un no nacional, aunque nada impide a los Estados ejercer dicha jurisdicción. ${ }^{89}$ En este sentido, pues, en los supuestos de los dos últimos tipos de infracciones del artículo $15-$ d) y e)—, lo establecido por el Segundo Protocolo de 1999 es la jurisdicción universal facultativa.

\section{CONCLUSIÓN}

Del relato de los esfuerzos jurídicos destinados a la protección en periodo de conflicto armado del patrimonio cultural en tanto que memoria colectiva de la humanidad podemos concluir una opinión satisfactoria respecto del mismo. A un instrumento jurídico internacional temprano en el tiempo (1954) hemos añadido un Segundo Protocolo de 1999 que desarrolla y perfecciona el derecho internacional humanitario aplicable a la materia. Además, este es un dato más para poder afirmar que el derecho internacional humanitario - tradicionalmente protector de la vida huma-

85 Artículo 16, párrafo 20., apartado a) del Segundo Protocolo de 1999.

86 Propuesta de los Estados Unidos de América, véase artículo 16, párrafo 2o., apartado b) del Segundo Protocolo de 1999. Henckaerts, Jean-Marie, op. cit., nota 51, p. 616.

87 Artículo 16, párrafo 2o., apartado a) del Segundo Protocolo de 1999. Ibidem, p. 616.

88 Artículo 8, párrafo 2o., apartado b), subapartado IX) del Estatuto de la Corte Penal Internacional de 1998.

89 Según artículo 16, párrafo 2o., apartado a) del Segundo Protocolo de 1999. 
na- incorpora, promueve y adapta jurídicamente nuevos intereses y dimensiones bajo su halo protector. ${ }^{90}$

En efecto, desde el punto de vista jurídico, el Segundo Protocolo actualiza la Convención de La Haya mediante la introducción de conceptos ya subrayados en el Protocolo Adicional I de 1977; aclara las obligaciones destinadas a la adopción de medidas preventivas y de difusión; perfecciona el mecanismo de control de la obligación de cumplimiento mediante la definición de las violaciones graves y a través de la imposición de los Estados del deber de ejercer jurisdicción sobre esas violaciones; extiende su ámbito de aplicación a los conflictos armados no internacionales; clarifica la conducta del adversario y la invocación de la "necesidad militar"; y muy en particular, brinda la oportunidad de hacer efectivo el régimen de "protección especial" reemplazándolo por un sistema nuevo y perfeccionado de "protección reforzada". ${ }^{91}$

No obstante, el relato de la voluntad y el compromiso estatal frente a esta normativa jurídico-internacional es decepcionante. De los actuales 191 Estados miembros de Naciones Unidas, sólo 110 son Estados partes en la Convención de La Haya de 1954; 88 son Estados partes en su Primer Protocolo; y 22 se han adherido al Segundo Protocolo de 1999 que, hasta hoy, se encuentra en vigor. Respecto a la Convención de 1954, en los últimos años se han incorporado Estados emblemáticos como China (en 2000) o extrañamente ausentes hasta entonces, como Portugal (en 2000) o Dinamarca (en 2003). También observamos ausencias significativas, pero que no resultan ser una novedad en cuanto a su voluntad de manifestar un compromiso internacional en ésta y en otras materias, como son Estados Unidos de América y Reino Unido.

Además, esta desidia estatal alcanza al sencillo sistema de catalogación y señalización propuesto $\mathrm{y}$, como hemos subrayado, el sistema de control mediante el envío de informes periódicos es ciertamente inoperante, a pesar de su carácter no contencioso.

Pero, quizás, lo más alarmante en esta valoración de la protección jurídica sea que el Estatuto del Tribunal Penal Internacional para la ex Yu-

90 Véase a este respecto, Sandoz, Yves, "Prioridades que han de definirse: tratar la protección de los bienes culturales como un capítulo del derecho internacional humanitario", Protección de los Bienes Culturales en caso de Conflicto Armado, Informe de la Reunión de Expertos (Ginebra, 5-6 de octubre de 2000), CICR — Servicio de Asesoramiento en Derecho Internacional Humanitario-, febrero de 2002, pp. 21-25.

91 Henckaerts, Jean-Marie, op. cit., nota 51, p. 619. 
goslavia de 1993 "olvide" tomar en consideración la misma Convención de La Haya; que el Estatuto de la Corte Penal Internacional de 1998 recoja como crimen de guerra contra el patrimonio cultural una definición un tanto opaca del mismo, lejos del espíritu y de la letra de la Convención de La Haya; $y$, por último, que en un reciente caso sobre la destrucción de un bien cultural Patrimonio Común de la Humanidad (la ciudad vieja de Dubrovnik) ante el Tribunal Penal Internacional para la antigua Yugoslavia, el fiscal no fundamente su alegato sobre la base de este régimen jurídico.

En definitiva, en su próximo 50o. aniversario de la Convención de La Haya de 1954, la comunidad internacional, el jurista y el Estado deberían aunar sus esfuerzos en pro de la asunción de compromisos jurídicos y de un efectivo y veraz cumplimiento de los ya asumidos en cuanto a la protección internacional del patrimonio cultural, vivo símbolo de los logros y esperanzas de la humanidad, puesto que como subrayaba Emmerich de Vattel en su obra The Law of Nations or the Principles of Natural Law:

For whatever cause a country be devasted, these buildings should be spared which are an honor to the human race and which do not add to the strength of the enemy, such as temples, tombs, public buildings and all edifices of remarkable beauty. What is gained by destroying them? It is the act of a declared enemy of the human race thus wantonly to deprive men of these monuments of art and models of architecture. ${ }^{92}$

92 Vattel, Emerich de, The Law of Nations or the Principles of Natural Law, applied to the Conduct and to the Afffairs of Nations and of Sovereigns, Washington D. C., Carnegie Institution of Washington, vol. 3, capítulo IX, p. 293, parágrafo 168, 1916 (reproduction of the 1758 edition). 